\title{
Studi Komparatif Pengaruh Metode Bagian dan Keseluruhan Terhadap Keterampilan Servis Kaki Bagian Dalam Bolavoli Gandu Level II
}

\author{
Agung Setyawan, Asim* \\ Universitas Negeri Malang, Jl. Semarang No. 5 Malang, Jawa Timur, Indonesia \\ *Penulis korespondensi, Surel: asim.fik@um.ac.id
}

Paper received: 4-2-2022; revised: 22-2-2022; accepted: 27-2-2022

\begin{abstract}
Physical education is a science in which there are aspects of knowledge, attitude, and movement. Volleyball learning at SMPN 3 Panggul is quite difficult to understand and do. Especially for service material, this can hinder students' motor development and mastery of volleyball skills. The aim of this study was to see the differences in the learning outcomes of the part method with the overall method on the inner leg service skills of Gandu volleyball level II for grade VII students of SMPN 3 Panggul Trenggalek. Researchers used the experimental method, where data analysis used the technique one way ANOVA with significance sign $=0.05$. The division of the randomly selected groups into 2 groups, performance tests and results tests which were taken by pretest and posttest. The results of the research in the section method group got an average pretest score, then the average score posttest of 61.33was 106.267 and in the overall method group had an average score of pretest 61.73 and a score of posttest 102.93, it can be concluded that learning foot service The part in the section method group was superior to the overall method group in the learning process of Gandu volleyball level II for students in class VII SMP Negeri 3 Panggul Trenggalek.
\end{abstract}

Keywords: inner foot service; part and whole method; gandu volleyball level ii

\begin{abstract}
Abstrak
Pendidikan Jasmani merupakan ilmu pengetahuan yang di dalamnya terdapat aspek pengetahuan, sikap, dan gerak. Pembelajaran bolavoli di SMPN 3 Panggul cukup sulit dipahami dan dilakukan. Khususnya materi servis, hal ini dapat menghambat perkembangan motorik siswa, dan penguasaan keterampilan bolavoli. Adapun penelitian ini bertujuan untuk melihat perbedaan hasil pembelajaran metode bagian dengan metode keseluruhan pada keterampilan servis kaki bagian dalam bolavoli gandu level II siswa kelas VII SMPN 3 Panggul Trenggalek. Peneliti menggunakan metode eksperimen, dimana analisis data menggunakan teknik one-way anova dengan signifikasi $a=0,05$. Pembagian kelompok yang dipilih secara acak menjadi 2 kelompok, tes kinerja dan tes hasil yang pengambilannya dengan pretest dan posttest. Hasil penelitian kelompok metode bagian mendapatkan skor rata-rata pretest 61,33, kemudian skor rata-rata posttest sebesar 106,267 dan pada kelompok metode keseluruhan memiliki rata-rata skor prestest 61,73 dan skor posttest 102,93, maka dapat disimpulkan pembelajaran servis kaki bagian dalam kelompok metode bagian lebih unggul dibandingkan dengan kelompok metode keseluruhan dalam proses pembelajaran bolavoli gandu level II untuk siswa di kelas VII SMP Negeri 3 Panggul Trenggalek.
\end{abstract}

Kata kunci: servis kaki bagian dalam; metode bagian dan keseluruhan; bolavoli gandu level ii

\section{Pendahuluan}

Pendidikan Jasmani adalah proses pembelajaran yang mengutamakan aktivitas jasmani (gerak) sebagai sarana untuk mencapai tujuan dari pendidikan. Pendidikan Jasmani merupakan salah satu bagian dari pendidikan yang di dalamnya terdapat aktivitas gerak (olahraga) sebagai sarana untuk memperoleh tujuan dari integral pendidikan (Winarno, 2010). Sedangkan menurut (Herdiyana \& Prakoso, 2016) "Pendidikan Jasmani adalah bagian tidak terpisahkan dalam seluruh pendidikan, yang pembelajarannya bertujuan untuk kesegaran jasmani, kemampuan motorik, berfikir kritis, penalaran, sosial, emosional, pola 
hidup sehat, sikap, dan aktivitas gerak, aktivitas olahraga, dan kesehatan, yang dipilih secara teratur dan direncanakan untuk memperoleh tujuan dari pendidikan*nasional”.

Bentuk aktivitas Pendidikan Jasmani berupa aktivitas olahraga ataupun non aktivitas olahraga. Pendidikan Jasmani mempunyai ruang lingkup antara lain: olahraga dan permainan, pengembangan diri, senam, ritmik, aktivitas air, pendidikan di luar kelas, dan kesehatan (Permendiknas, 2006). Satu satu bagian dari ruang lingkup pendidikan jasmani yang digunakan untuk mencapai tujuan pendidikan adalah permainan bolavoli. Permainan bolavoli ialah permainan yang tersusun oleh 2 tim, satu satu tim terdiri 6 pemain, lapangan permainan dipisahkan oleh net, setiap tim berusaha menjatuhkan bola ke lapangan lawan melalui atas net, dengan ketentuan setiap tim berhak memukul bola maksimal hingga tiga kali sentuhan atau pukulan (kecuali block atau membendung) tetapi seorang pemain tidak diperbolehkan memukul bola sampai 2 kali secara berturut-turut (Mustafa, 2015).

Berdasarkan wawancara dengan guru pendidikan jasmani SMPN 3 Panggul Trenggalek, dibandingkan teknik passing, teknik servis sulit dipahami atau dilakukan karena servis membutuhkan kekuatan lengan dan bola harus melewati net. Keadaan ini dapat menghambat perkembangan motorik siswa, dan penguasaan keterampilan permainan bolavoli. Oleh sebab itu modifikasi dalam permainan bolavoli sangat perlu dilakukan, karena dengan memodifikasi akan memudahkan siswa untuk menguasai keterampilan servis permainan bola voli.

Permainan bola voli gandu adalah permainan hasil dari kombinasi dari sepak takraw dan bolavoli mini yang sudah dimodifikasi (Asim, 2001). Cara bermain bolavoli gandu level II bisa menggunakan semua bagian tubuh untuk melakukan voli atau memantulkan bola. Setiap tim maksimal 5 kali kesempatan untuk memvoli atau memantulkan bola dan bola boleh memantul ke tanah 1 kali. Berdasarkan jenisnya servis bolavoli gandu level II ada 4 macam yakni servis atas menggunakan lengan, servis bawah menggunakan lengan, jump service, servis menggunakan kaki. Servis menggunakan kaki dilakukan dengan kaki bagian dalam, luar, dan punggung. Servis menggunakan kaki bagian dalam bolavoli gandu level II dapat digunakan sebagai pilihan pembelajaran permainan bolavoli selain servis bolavoli menggunakan lengan.

Pembelajaran metode bagian dan keseluruhan bisa digunakan untuk meningkatkan keterampilan olahraga termasuk keterampilan servis kaki bagian dalam. Metode bagian merupakan proses pembelajaran dengan membagi satu pembelajaran ke beberapa bagian, kemudian sesudah siswa bisa menguasai bagian-bagian dari pembelajaran tersebut siswa harus menggabungkan menjadi satu rangkaian pembelajaran yang utuh, metode ini bertujuan agar pembelajaran lebih mudah dipahami dan dikuasai bagi siswa (Firdaus, 2014). Metode keseluruhan merupakan suatu proses pembelajaran yang utuh dan di ulang-ulang sampai pembelajaran tersebut dapat dipahami dan dikuasai oleh siswa (Rianto, 2016). Kedua metode pembelajaran ini memiliki karakteristik dan fokus pembelajaran yang berbeda, sehingga pengaruh peningkatan kemampuan servis kaki bagian dalam bolavoli gandu level II belum diketahui.

\section{Metode}

Penelitian ini di desain menggunakan metode eksperimen dengan membagi 2 kelompok yang dipilih secara acak, tes kinerja dan tes hasil yang pengambilannya dengan pretest dan posttest. Analisis data dalam penelitian ini menggunakan teknik one way anova. Tata cara pengambilan data diawali dengan langkah persiapan penelitian, pelaksanaan pretest dan posttest. Jumlah dari subjek penelitian sebanyak 30 anak dengan siswa laki-laki berjumlah 14 
anak dan siswa perempuan berjumlah 16 anak, kemudian membagi menjadi 2 kelompok pembelajaran yang dipilih secara acak yaitu: (1) 15 siswa kelompok pembelajaran metode bagian, (2) 15 siswa kelompok pembelajaran metode keseluruhan. Instrumen dalam penelitian ini menggunakan tes kinerja dan tes hasil servis kaki bagian dalam bolavoli gandu level II. Proses pengolahan dari data penelitian menggunakan aplikasi SPSS versi 23 for windows.

\section{Hasil dan Pembahasan}

Berdasarkan uji hipotesis yang menggunakan analisis one way anova: (1) pembelajaran metode bagian berpengaruh pada hasil kemampuan servis kaki bagian dalam yang probabilitasnya sebesar 0,000 kurang dari 0,05, artinya ada perbedaan rata-rata skor sebelum diberikan pembelajaran dan sesudah diberikan pembelajaran metode bagian, (2) pembelajaran metode keseluruhan berpengaruh pada hasil kemampuan servis kaki bagian dalam yang probabilitasnya sebesar 0,000 kurang dari 0,05 , artinya ada perbedaan rata-rata skor sebelum diberikan pembelajaran dan sesudah diberikan pembelajaran metode keseluruhan. Analisis data menggunakan one way anova pada kelompok metode bagian dan kelompok metode keseluruhan dari hasil posttest untuk mengetahui apakah ada perbedaan pengaruh di kedua kelompok tersebut. Berikut tabel analisis one way anova dari hasil posttest kemampuan servis kaki bagian dalam kelompok metode bagian dan kelompok metode keseluruhan.

Tabel 1. Analisis One Way Anova Posttest Pembelajaran Servis Kaki Bagian Dalam Pada Kelompok Pembelajaran Metode Bagian dan Pembelajaran Metode Keseluruhan

\begin{tabular}{llllll}
\hline $\begin{array}{l}\text { Pembelajaran Metode Bagian dan } \\
\text { Metode Keseluruhan }\end{array}$ & $\begin{array}{l}\text { Sum*of } \\
\text { Square }\end{array}$ & df & Mean*Square & F & Sig \\
\hline Between groups within group total & 246,533 & 1 & 246,533 & 8,172 & ,008 \\
& 844,667 & 28 & 30,167 & & \\
& 1091,200 & 29 & & & \\
\hline
\end{tabular}

Hasil analisis One Way Anova memperoleh probabilitas sebesar 0,008 kurang dari 0,05 artinya ada perbedaan skor dari rata-rata kemampuan servis kaki bagian dalam pada posttest kelompok metode bagian dan posttest kelompok metode keseluruhan bolavoli gandu level II. Dari hasil pemaparan data diatas hasil pretest kelompok metode bagian memperoleh rata-rata 61,33 dan posttest memperoleh rata-rata sebesar 106,267, sementara kelompok metode keseluruhan hasil pretest memperoleh rata-rata 61,73 dan posttest memperoleh rata-rata sebesar 102,93. Kesimpulannya bahwa pembelajaran servis kaki bagian dalam bolavoli gandu level II kelompok metode bagian lebih unggul/baik dibandingkan kelompok menggunakan metode keseluruhan pada siswa di kelas VII SMPN 3 Panggul Trenggalek.

Pembelajaran metode bagian terbukti berpengaruh terhadap hasil keterampilan servis kaki bagian dalam bolavoli gandu level II bagi siswa kelas VII SMPN 3 Panggul Trenggalek. Hasil dari analisis varian one way anova pada kelompok metode bagian memiliki taraf signifikasi 0,000 kurang dari 0,05, dengan nilai rata-rata keterampilan servis kaki bagian dalam bolavoli gandu level II yaitu pretest 61,33 dan posttest 106,267 menunjukkan adanya peningkatan keterampilan. Kesimpulannya pembelajaran menggunakan metode bagian berpengaruh terhadap hasil keterampilan servis kaki bagian dalam bolavoli gandu level II siswa kelas VII SMPN 3 Panggul Trenggalek. Metode bagian adalah metode pembelajaran dengan membagi keterampilan menjadi beberapa bagian (Prastowo, 2014). Pembelajaran metode bagian siswa 
dapat menguasai bagian per bagian dari keterampilan yang dipelajari dan perkembangan motorik siswa akan meningkat karena diakhir pembelajaran siswa harus menggabungkan bagian-bagian menjadi satu.

Berdasarkan hasil analisis varian dengan teknik one way anova pada siswa kelompok metode keseluruhan memiliki taraf signifikasi sebesar 0,000 kurang dari 0,05 dari rata-rata skor keterampilan servis kaki bagian dalam bolavoli gandu level II yaitu pretest 61,73 dan posttest 102,93 menunjukkan adanya peningkatan keterampilan. Pembelajaran kelompok metode keseluruhan memiliki pengaruh pada hasil kemampuan servis kaki bagian dalam bolavoli gandu level II siswa kelas VII SMPN 3 Panggul Trenggalek. Menurut (Rianto, 2016) "Metode keseluruhan adalah metode pembelajaran yang dilakukan secara utuh dan berulangulang sampai siswa memahami dan menguasai materi yang diajarkan". Metode keseluruhan terdapat banyak pengulangan gerak dalam satu gerakan utuh pembelajaran servis kaki bagian dalam, pengulangan tersebut dapat meningkatkan motorik siswa.

Hasil analisis varian dengan teknik one way anova, hasil posttest dari 2 kelompok metode bagian dan kelompok metode keseluruhan diperoleh Signifikasi 0,008 kurang dari 0,05 artinya ada perbedaan hasil antara kelompok metode bagian dengan kelompok metode keseluruhan yang cukup signifikan pada hasil pembelajaran kemampuan servis kaki bagian dalam bola voli gandu level II. Nilai rata-rata skor yang sudah dipaparkan dapat disimpulkan bahwa pembelajaran servis kaki bagian dalam kelompok metode bagian lebih unggul/baik dibandingkan kelompok metode keseluruhan pada siswa di kelas VII SMPN 3 Panggul Trenggalek.

Pembelajaran servis kaki bagian dalam pada permainan bola voli gandu level II menggunakan metode bagian dan keseluruhan dapat meningkatkan perkembangan kemampuan motorik seorang siswa, hal ini disebabkan pembelajaran bolavoli gandu level II menyertakan semua anggota tubuh untuk memvoli bola. Menggerakkan otot-otot pada lengan dan kaki berkaitan dengan keterampilan motorik kasar. Seperti pendapat dari Taylor (2007) bahwa keterampilan motorik kasar adalah gerakan-gerakan yang besar oleh otot lengan dan kaki. Menurut Tugas dari motorik kasar meliputi kekuatan tangan, lompat, berjalan, dan berdiri dengan satu kaki (Piek dkk., 2008). Tidak hanya keterampilan motorik kasar yang mendapat pengaruh dari pembelajaran servis kaki bagian dalam bolavoli gandu level II namun keterampilan motorik halus pada otot-otot kecil seperti di pergelangan tangan dan jari-jari tangan. Menurut (Aslan, 2016) "Keterampilan motorik halus adalah keterampilan dalam penggunaan otot-otot kecil yang melibatkan gerakan fungsi anggota tubuh untuk memanipulasi suatu objek". Menurut (Piek dkk., 2008) tugas dari motorik halus adalah memindahkan suatu barang ke dalam kotak, menggeser suatu barang selambat dan sehalus mungkin.

Walaupun pembelajaran servis kaki bagian dalam memiliki tingkat kesulitan yang cukup sulit karena siswa belum pernah mengetahui dan melakukan sebelumnya, namun peran guru tetap bertanggungjawab untuk menciptakan motivasi. Motivasi adalah dorongan untuk menguatkan manusia agar mencapai kemampuannya yang maksimal dan mengatasi hambatan yang sedang di alaminya (Tohidi \& Jabbari, 2012). Motivasi inilah bisa mempengaruhi psikologis siswa yang menurutnya teknik ini sulit akan menjadi mudah. Dengan semangat belajar dan optimis yang besar untuk berlatih teknik servis kaki bagian dalam bisa berperan dalam aspek sosial. Aspek sosial bertujuan agar siswa mempelajari dan menerapkan aturan- 
aturan tertentu sesuai konteknya (misalnya, keterampilan bekerja sama untuk menghadapi kehilangan poin selama permainan bolavoli). Dalam bolavoli gandu level II bentuk kerja sama untuk mencapai tujuan bersama untuk menguasai keterampilan servis kaki bagian dalam, kerja sama ini akan memunculkan komunikasi, rasa menghormati dan percaya kepada teman untuk mencapai tujuan pembelajaran.

\section{Simpulan}

Berdasarkan hasil penelitian peneliti mengambil kesimpulan yaitu: 1) penggunaan metode bagian untuk pembelajaran servis kaki bagian dalam bolavoli gandu level II berpengaruh secara signifikan dengan rata-rata skor pretest 61,33 dan posttest 106,267, 2) penggunaan metode keseluruhan untuk pembelajaran servis kaki bagian dalam bolavoli gandu level II berpengaruh secara signifikan dengan rata-rata skor pretest 61,73 dan posttest 102,93, 3) pembelajaran metode bagian lebih unggul dibandingkan dengan pembelajaran metode*keseluruhan terhadap keterampilan servis kaki bagian dalam bolavoli gandu level II bagi siswa kelas VII SMPN 3 Panggul Trenggalek.

\section{Daftar Rujukan}

Asim, A. (2001.) Pola Pembelajaran Bolavoli Gandu Untuk Kesegaran Jasmani: Eksperimen di Sekolah Dasar Negeri Desa Karanggandu. Cet. I. Malang: Wineka Media

Aslan, S. (2016). An Evaluation of Fine and Gross Motor Skills in Adolescents with Down Syndromes. International Journal of Science Culture and Sport, 4(16), 187-187.

Firdaus, H. (2014). Perbandingan Metode Pembelajaran Bagian (Part-Method) Dan Metode Pembelajaran Keseluruhan (Whole-Method) Terhadap Kemampuan Siswa Dalam Melakukan Smash Bolavoli (Studi Pada Kegiatan Ekstrakulikuler Di SMA Negeri 1 Kamal). Jurnal Pendidikan Olahraga dan Kesehatan, 2(2).

Herdiyana, A., \& Prakoso, G. P. W. (2016). Pembelajaran Pendidikan Jasmani Yang Mengacu Pada Pembiasaan Sikap Fair Play Dan Kepercayaan Pada Peserta Didik. Jorpres (Jurnal Olahraga Prestasi), 12(1).

Mustafa, P. S. (2015). Panduan Variasi Latihan Service Atas Permainan Bolavoli untuk Peserta Ekstrakurikuler Bolavoli di SMK Negeri 4 Malang. Fakultas Ilmu Keolahragaan Universitas Negeri Malang.

Depdiknas. (2006). Permendiknas No. 22 Tentang Tujuan Pendidikan Jasmani Olahraga dan Kesehatan. Jakarta: Depdiknas.

Piek, J. P., Dawson, L., Smith, L. M., \& Gasson, N. (2008). The Role of Early Fine and Gross Motor Development on Later Motor and Cognitive Ability. Human Movement Science, 27(5), 668-681.

Prastowo, G. (2014). Pengaruh Metode Pembelajaran Part Practice Terhadap Hasil Belajar Shooting Bola Basket (Studi Pada Siswa Kelas XI-IPS SMA Negeri 1 Cerme). Jurnal Pendidikan Olahraga dan Kesehatan, $2(3)$.

Rianto, H. (2016). Perbandingan Metode Pembelajaran Part Practice dan Whole Practice Terhadap Hasil Belajar Service Bawah Bolavoli (Studi Pada Siswa kelas VII SMPN 2 Arjasa Sumenep Tahun Ajaran 2014 2015). Jurnal Pendidikan Olahraga dan Kesehatan, 3(3).

Tohidi, H., \& Jabbari, M. M. (2012). The Effects of Motivation in Education. Procedia - Social and Behavioral Sciences, 31, 820-824.

Winarno, M. E. 2010. Evaluasi Dalam Pendidikan Jasmani. (Cet. 1). Jakarta: Center for Human Capacity Development. 